\title{
Chlamydial infection as a possible aetiological factor in the Guillain-Barré syndrome
}

\author{
C. E. H. GRATTAN* \\ M.B., M.R.C.P.
}

\author{
P. BERMAN \\ M.B., M.R.C.P.
}

Musgrove Park Hospital, Taunton and

Bristol Royal Infirmary, Bristol BS2 $8 \mathrm{HW}$

\begin{abstract}
Summary
Two cases of Guillain-Barré syndrome are reported with serological evidence of recent Chlamydia psittaci infection. It is suggested that the chlamydial infection may have precipitated the neurological syndrome.
\end{abstract}

\section{Introduction}

Guillain-Barré syndrome may follow a wide variety of events including infection with viral, mycoplasmal and some bacterial agents (Hughes, 1978; Leneman, 1966). We report two cases of GuillainBarré syndrome with serological evidence of recent Chlamydia psittaci infection.

\section{Case reports}

\section{Case 1}

A 14-year-old boy was admitted with a five-day history of progressive weakness affecting all four limbs. Three weeks earlier he had developed a productive cough which had been successfully treated with talampicillin. He suffered from asthma and was receiving sodium cromoglycate.

On examination there was widespread inspiratory wheeze and a flaccid tetraparesis with relative sparing of distal muscle power. All tendon reflexes were diminished but there was no detectable sensory impairment. Examination of the cerebrospinal fluid (CSF) showed a protein of $1.26 \mathrm{~g} /$ litre with $7 \times 10^{\circ}$ lymphocytes/litre. Serum complement fixation titres against $C$. psittaci antigen were 768, 6 days after the onset of neurological symptoms, 384 after 15 days and 384 after 40 days. Fluorescent antibody titres were 768,768 and 512 respectively. Screening tests for recent viral and mycoplasmal infection were negative.

\footnotetext{
*Present address: St. John's Hospital for Diseases of the Skin, Homerton Grove, London E9.
}

Within five days of admission there was marked weakness of all limb muscles with complete areflexia and the appearance of a left external rectus weakness. He developed a productive cough with clinical and radiological evidence of left lower lobe consolidation, which resolved after 14 days treatment with tetracycline. Although his vital capacity fell to $1 \cdot 3$ litres on one occasion during this period, assisted ventilation was not required. Plasma exchange was performed 48 days after admission when limb paralysis was complete, with the exception of the small hand muscles and toe flexors. This procedure was repeated 10 days later and was followed by sustained clinical improvement.

\section{Case 2}

A 76-year-old active market gardener was admitted with a four-day history of progressive weakness affecting his arms and legs. Three weeks earlier he had developed a cough, productive of yellow sputum, for which he had been treated with amoxycillin for 4 days before admission. Otherwise, he took no drugs and gave no history of previous illness.

On examination, there was a flaccid tetraparesis with some sparing of power in the hands. All reflexes were absent with the exception of both biceps jerks. Sensation was normal apart from diminished joint position sense in the digits. Examination of the CSF showed a protein of $0.56 \mathrm{~g} /$ litre with no white cells. A chest X-ray was normal. Serum fixation titres against Chlamydial group antigen were in excess of 640 on two occasions separated by 7 days. Screening tests for recent viral and mycoplasmal infection were negative.

Tracheostomy and assisted ventilation were necessary for worsening respiratory failure. Treatment with doxycycline was initiated, but was changed to erythromycin after an erythematous rash developed. A week later he became hypotensive and shocked. 
Despite treatment with heparin and hydrocortisone he died after 6 days.

At post-mortem there was extensive bronchopneumonia. There was organizing pulmonary infarction in both lower lobes and a fresh pulmonary embolus occluded the right and left main pulmonary arteries.

\section{Discussion}

A recent report (PHLS Communicable Diseases Centre, 1981) noted an increase in reported cases of human psittacosis in 1980 compared with 1979. Diagnosis was made by the demonstration of rising complement fixation titres in paired sera or a single titre greater than 128. Cases diagnosed on a single high titre and in which pneumonia was not reported accounted for $55 \%$ of this increase.

An association between the Guillain-Barré syndrome and positive chlamydial serology has been suggested in the past (Melnick and Flewett, 1964). Four cases were described but only one had significantly rising titres. The others had low titres of complement fixing atibody to Chlamydia psittaci and evidence of recent viral infection.
The finding of high titres of complement fixing antibodies in our two patients suggests that recent chlamydial infection had occurred. Both patients had a preceding respiratory infection but only one (Case 2) admitted contact with psittacine birds. It is possible that the chlamydial infection precipitated the neurological syndrome.

\section{Acknowledgments}

We thank Dr M. J. Campbell and Dr D. B. Yates for permission to report on their patients and Dr S. Richmond, Bristol Public Health Laboratory, for helpful advice.

\section{References}

HugHes, R.A.C. (1978) Acute inflammatory polyneuropathy. British Journal of Hospital Medicine, 20, 688.

LENEMAN, F. (1966) Guillain-Barré syndrome; review of 1,100 cases. Archives of Internal Medicine, 118, 139.

Melnick, S.C. \& FleweTt, T.H. (1964) Role of infection in the Guillain-Barré syndrome. Journal of Neurology, Neurosurgery and Psychiatry, 27, 395.

PhlS Communicable Disease Surveillance Centre (1981) Trends in human ornithosis/psittacosis, 1975-80. British Medical Journal, 283, 1411 . 